\title{
New-Generation Quantitative Immunoassays for SARS- CoV-2 Antibody Detection: Need for Harmonization
}

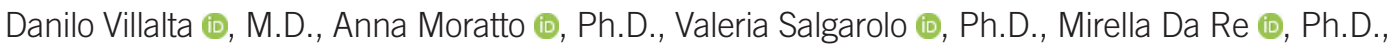 \\ Roberto Giacomello $\mathbb{C}^{\circ}$, Ph.D., and Giacomo Malipiero 리, M.D. \\ Department of Immunology and Allergy, S. Maria degli Angeli Hospital, Pordenone, Italy
}

\section{Dear Editor,}

Since March 2020, many qualitative or semi-quantitative serologic assays to detect antibodies against severe acute respiratory syndrome-coronavirus 2 (SARS-CoV-2) have become commercially available. Harristshøj, et al. [1] compared the results of 16 serological assays on a large number of patients and controls, showing differences in accuracy, despite the majority of automated assays for total (IgG+lgM) and IgG antibody detection reaching the predefined criteria for acceptable performance. Additionally, the antibody response appeared to be the strongest among patients with more severe disease [1]. Since quantitative determination of SARS-CoV-2 antibodies may be important for longitudinal monitoring of the antibody response in patients and in response to a vaccine, a new generation of quantitative immunoassays for SARS-CoV-2 antibody detection was recently launched [2-7]. However, to date, few independent studies evaluating these assays have been published, and no studies have compared the quantitative data obtained with these novel immunoassays.

We compared the results of four new-generation fully automated immunoassays for quantitative SARS-CoV-2 IgG antibody detection using a total of 123 serum samples, including 93 samples from patients diagnosed as having coronavirus disease 2019 (COVID-19; 44 with mild, 35 with severe, and 14 with critical disease) and 30 samples from patients with other acute viral diseases (Epstein-Barr virus, cytomegalovirus, influenza, adenovirus) as controls. Sera from patients with COVID-19 were collected between 19 and 30 days from symptom onset. All serum samples were collected at Pordenone Hospital (Italy) from March to June 2020. The study was approved by the Institutional Review Board of the Pordenone Hospital, and informed consent was obtained from the patients. Two of the assays use an antigen of the recombinant receptor-binding domain (RBD) of the spike (S) protein (sCOVG, Siemens, Tarrytow, NY, USA, and Maglumi SARS-CoV-2 S-RBD IgG, Snibe, Shenzhen, China), one uses a recombinant S1 protein (SARS-CoV-2-Sp1 IgG EliA, Thermo Fisher, Uppsala, Sweden), and one uses a recombinant trimeric protein (S1+S2+RBD) (Liaison SARS-CoV2 Trimeric S IgG, Diasorin, Saluggia, Italy). All samples were processed according to the manufacturers' instructions using an automated chemiluminescence immunoassay platform (Advia Centaur XPT [Siemens], Maglumi [Snibe], and Liaison XL [Diasorin]) and an automated fluoroenzyme immunoassay platform (ImmunoCAP 250 [Thermo Fisher]). All assay results are expressed in arbitrary units (AU)/ $\mathrm{mL}$, and the dynamic range of the Siemens, Snibe, Diasorin, and Thermo Fisher immunoassays was 0.5-150 AU/mL, 0.18$100 \mathrm{AU} / \mathrm{mL}, 1.85-800 \mathrm{AU} / \mathrm{mL}$, and 0.7-204 AU/mL, respectively. Samples with antibody levels exceeding the upper limit of
Received: March 14, 2021

Revision received: April 14, 2021

Accepted: July 12, 2021

Corresponding author: Danilo Villalta, M.D. Department of Immunology and Allergy, S. Maria degli Angeli Hospital, 24 Via Montereale, Pordenone 33170, Italy Tel: +39-0434-399647, E-mail: danilo.villalta@asfo.sanita.fvg.it

\section{(c) (1) $\Theta$}

(C) Korean Society for Laboratory Medicine

This is an Open Access article distributed under the terms of the Creative Commons Attribution Non-Commercial License (https://creativecommons.org/licenses/by-nc/4.0) which permits unrestricted non-commercial use, distribution, and reproduction in any medium, provided the original work is properly cited. 
quantification were re-assayed after automated (manual for Diasorin) pre-dilution with the diluent provided by the manufacturer.

Statistical analyses were performed using MedCalc software version 15.2.1 (Ostend, Belgium). Sensitivity was defined as the proportion of correctly identified patients with COVID-19 infection and specificity as 100 minus the proportion of control population found positive for SARS-Cov-2 antibodies. The MannWhitney $U$ test was used for the comparison of continuous variables. $P<0.05$ was considered statistically significant. Correlations between the different assays were calculated using correlation coefficient ( $r$ ) and Passing-Bablok tests. Seven of the 93 samples from COVID-19 patients and all control samples showed a negative result with all four assays (sensitivity: 92.5\%, 95\% confidence interval [Cl]: 85.1\%-96.2\%; specificity: 100\%, 95\% Cl: 88.4\%-100\%; overall agreement: 100\%). The seven COVID-19 patients who had a negative result from the antibody assays all showed mild symptoms. A significantly higher antibody level was detected in patients with severe or critical symptoms than in patients with mild symptoms ( $P \leq 0.0002)$ (Fig. 1$)$.
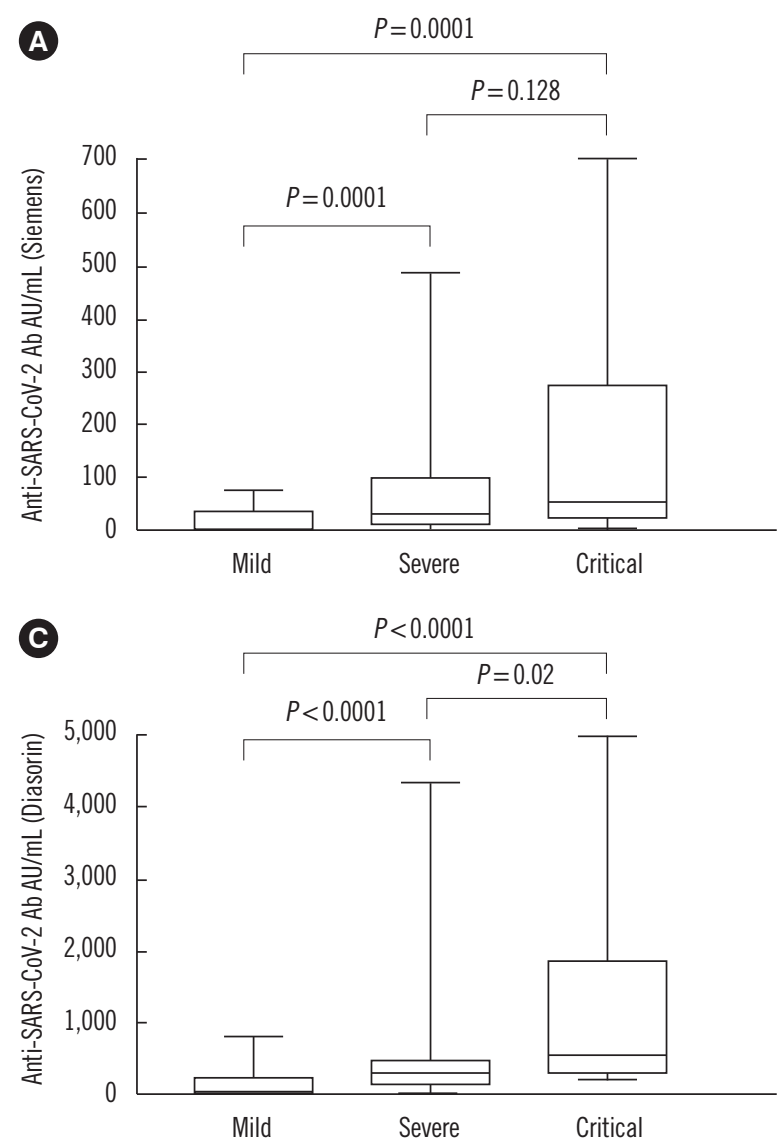

Quantitative comparison of SARS-CoV-2 antibody levels showed a very high correlation between the Siemens and Snibe assays $(r=0.920)$, between the Thermo Fisher and Siemens assays $(r=0.930)$, and between the Thermo Fisher and Snibe assays $(r=0.930)$. High correlations were observed between the Diasorin and Siemens assays ( $r=0.871)$, between the Diasorin and Snibe assays $(r=0.797)$, and between the Diasorin and Thermo Fisher assays $(r=0.810)$. However, the Passing-Bablok regression test (Fig. 2) showed different absolute values among the assays and, with the exception of the Snibe vs. Siemens and Snibe vs. Thermo Fisher comparisons, also showed significant deviation from linearity. The relatively weak correlations between Diasorin and the other assays could be explained by the trimeric nature of the antigen used in this assay, likely detecting an antibody subset not detected by the other assays.

In conclusion, with the limitation of the small sample size, perfect qualitative agreement of results was obtained among four new-generation immunoassays, whereas some differences in the quantitative results were found, indicating that commutabil-

B
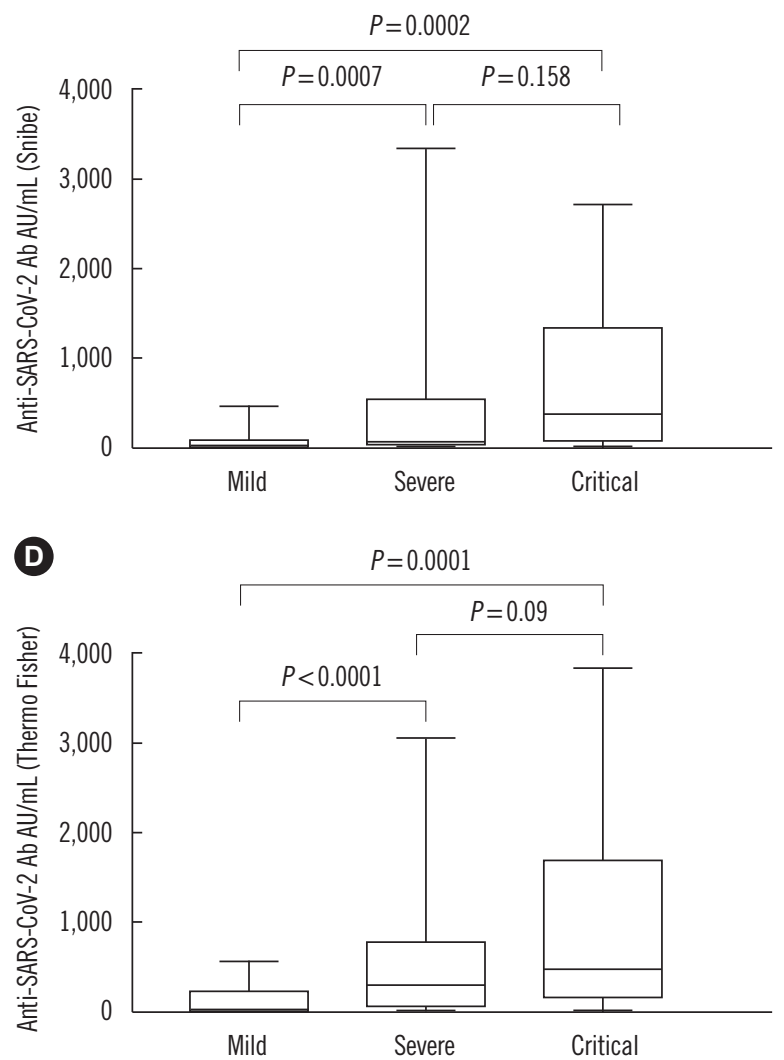

Fig. 1. Antibody levels in patients with mild $(N=44)$, severe $(N=35)$, and critical $(N=14)$ COVID-19 symptoms. Abbreviations: SARS-CoV-2, severe acute respiratory syndrome-coronavirus 2; Ab, antibody. 

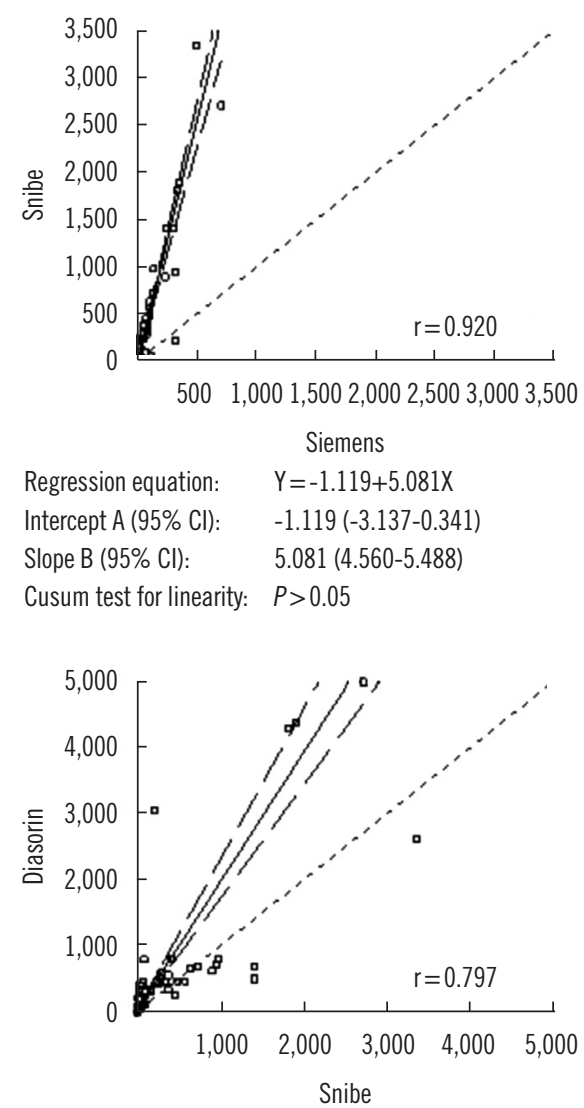

Regression equation: Intercept A $(95 \% \mathrm{Cl})$ : Slope B $(95 \% \mathrm{Cl})$ : Cusum test for linearity:

$$
\mathrm{Y}=-6.757+0.510 \mathrm{X}
$$$$
-6.757(-17.752--0.073)
$$
$0.519(0.438-0.583)$

$P<0.01$

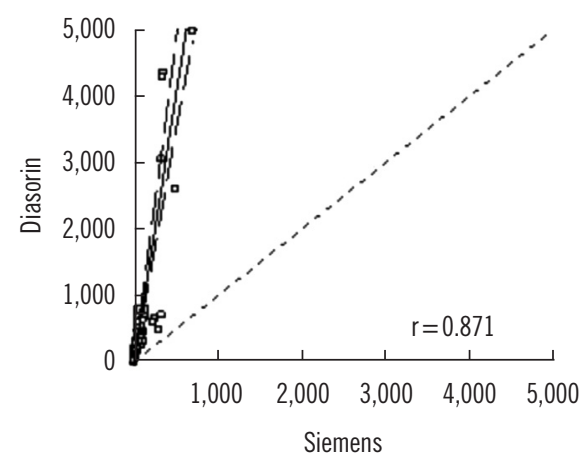

$\mathrm{Y}=18.516+7.991 \mathrm{X}$

$18.516(6.054-26.628)$

$7.991(6.908-9.637)$

$P<0.01$

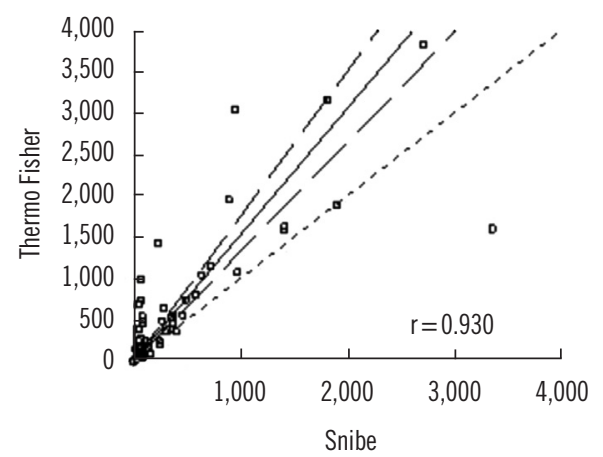

$\mathrm{Y}=0.100+0.654 \mathrm{X}$

$0.100(-0.989-2.332)$

$0.654(0.571-0.754)$

$P>0.05$

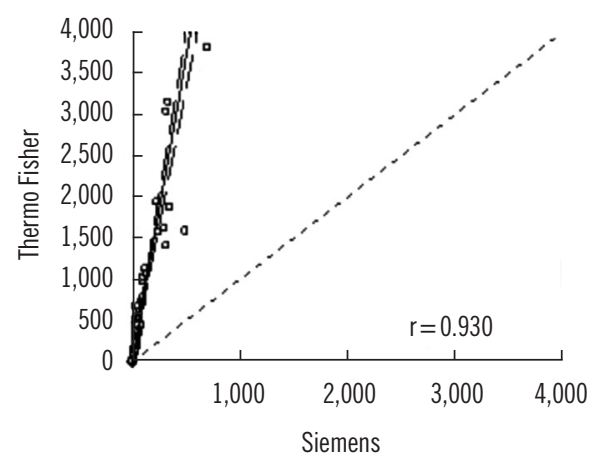

$Y=-2.994+7.281 \mathrm{X}$

$-2.944(-8.070-0.186)$

7.281 (6.563-7.997)

$P<0.01$

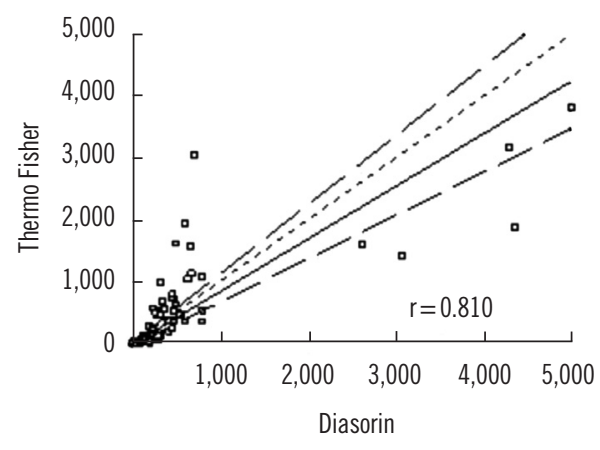

$\mathrm{Y}=19.062+1.175 \mathrm{X}$

19.062 (12.316-32.948)

1.175 (0.893-1.422)

$P<0.01$

Fig. 2. Passing-Bablok regression test comparing SARS-CoV-2 antibody levels using different immunoassays.

ity of results among these assays is not possible. Since the first WHO International Standards for anti-SARS-CoV-2 Ig (code 20/ 136) was recently prepared [8], all manufacturers should use this standard for calibration of their quantitative serological assays, enabling accurate comparisons, at least for assays using the same antigen. Harmonization of results remains essential for the longitudinal monitoring of antibody response in patients after recovery and to help elucidate the response to vaccination.

\section{ORCID}

Danilo Villalta

Anna Moratto

Valeria Salgarolo

Mirella Da Re

Roberto Giacomello

Giacomo Malipiero https://orcid.org/0000-0002-8865-4150 https://orcid.org/0000-0002-4349-2346 https://orcid.org/0000-0002-2890-9553 https://orcid.org/0000-0002-9852-1431 https://orcid.org/0000-0001-7864-6010 https://orcid.org/0000-0002-2914-8258

\section{REFERENCES}

1. Harristshøj LH, Gybel-Brask M, Afzal S, Kamstrup PR, Jørgensen CS, Tomsen MK, et al. Comparison of 16 serological SARS-CoV-2 immunoassays in 16 clinical laboratories. J Clin Microbiol 2021;59:e02596-20.

2. Infantino M, Damiani A, Li Gobbi F, Grossi V, Lari B, Macchia D, et al. Serological assays for SARS-CoV-2 infectious disease: benefits, limitations and perspectives. Isr Med Assoc J 2020;22:203-20.

3. Higgins V, Fabros A, Kulasingam V. Quantitative measurement of antiSARS-CoV-2 antibodies: analytical and clinical evaluation. J Clin Microbiol 2021;59:e03149-20.

4. Noda K, Matsuda K, Yagishita S, Maeda K, Akiyama Y, Terada-Hirashima J, et al. A novel highly quantitative and reproducible assay for the detection of anti-SARS-CoV-2 IgG and IgM antibodies. Sci Rep 2021; 11:5198.

5. Bonelli F, Blocki FA, Bunnell T, Chu E, De La OA, Grenache DG, et al. Evaluation of the automated LIAISON SARS-CoV-2 TrimericS IgG assay for detection of circulating antibodies. Clin Chem Lab Med 2021;59: 1463-7.

6. Narasimhan M, Mahimainathan L, Araj E, Clark AE, Markantonis J, Green A, et al. Clinical evaluation of the Abbott Alinity SARS-CoV-2 spike-spe- 
cific quantitative IgG and IgM assays among infected, recovered, and vaccinated groups. J Clin Microbiol 2021;59: e0038821.

7. Irsara C, Egger AE, Prokop W, Nairz M, Loacker L, Sahanic S, et al. Clinical validation of the Siemens quantitative SARS-CoV2 spike IgG assay (sCOVG) reveals improved sensitivity and a good correlation with virus neutralization titers. Clin Chem Lab Med 2021;59:1453-62.

8. National Institute for Biological Standards and Control. First WHO International Standard Anti-SARS-CoV-2 Immunoglobulin (Human). https:// www.nibsc.org/products/brm_product_catalogue/detail_page.aspx?catid= 20/136 (Updated on Jan 21, 2021). 